\title{
Deficiency of co-chaperone immunophilin FKBP52 compromises sperm fertilizing capacity
}

\author{
Jiyoung Hong ${ }^{1}$, Sung Tae Kim ${ }^{1}$, Susanne Tranguch², David F Smith ${ }^{4}$ and Sudhansu K Dey ${ }^{1,2,3}$ \\ ${ }^{1}$ Departments of Pediatrics, ${ }^{2}$ Cell and Developmental Biology, ${ }^{3}$ Pharmacology, Vanderbilt University Medical Center, \\ Nashville, Tennessee 37232, USA and ${ }^{4}$ Department of Biochemistry and Molecular Biology, Mayo Clinic, Scottsdale, \\ Arizona 85259, USA
}

Correspondence should be addressed to $S K$ Dey, Division of Reproductive and Developmental Biology, Department of Pediatrics, Vanderbilt University Medical Center, MCN-D4100, Nashville, Tennessee 37232-2678, USA;

Email: sk.dey@vanderbilt.edu

J Hong and S T Kim contributed equally to this work

S T Kim is now at Department of OB-GYN, Washington University, St Louis, Missouri, USA

\begin{abstract}
FKBP52 is a member of the FK506-binding family of immunophilins and serves as a co-chaperone for steroid hormone nuclear receptors to govern appropriate hormone action in target tissues. Male mice missing Fkbp52 are infertile, and this infertility has been ascribed to compromised sensitivity of the anterior prostate, external genitalia, and other accessory sex organs to androgen. Here, we show additional defects contributing to infertility. We found that epididymal $F k_{b p 52^{-1-}}$ sperm are sparse often with aberrant morphology, and they have reduced fertilizing capacity. This phenotype, initially observed in null males on a C57BL/6/129 background, is also maintained on a CD1 background. Expression studies show that while FKBP52 and androgen receptor are co-expressed in similar cell types in the epididymis, FKBP52 is also present in epididymal sperm flagella. Collectively, our results suggest that reduced number and abnormal morphology contribute to compromised fertilizing capacity of $F k_{b p 52^{-/-}}$ sperm. This study is clinically relevant because unraveling the role of immunophilin signaling in male fertility will help identify new targets for male contraceptives and/or alleviate male infertility.

Reproduction (2007) 133 395-403
\end{abstract}

\section{Introduction}

Sperm maturation requires passage through the androgenresponsive epididymis. The epididymis is composed of three regions, the caput, corpus, and cauda, and each region contributes to specific functions, such as maturation, transport, concentration, and storage of sperm. Through maturation, sperm acquire motility and competence to undergo capacitation, physiological changes that culminate in sperm's capacity to interact with and fertilize an oocyte (Orgebin-Crist 1967, Cornwall \& Hsia 1997, Robaire \& Hermo 2002, Nixon et al. 2005). The molecular mechanisms underlying these processes, however, are not completely understood.

Normal functioning of nuclear steroid hormone receptors is dependent on interactions with the molecular chaperone machinery to maintain a functional state competent for hormone binding and subsequent transcriptional activation (reviewed in Pratt \& Toft 2003). Functionally mature steroid receptor complexes consist of a receptor monomer, a $90 \mathrm{kDa}$ heat shock protein (HSP) dimer, the co-chaperone p23, and one of the four HSP co-chaperones that contain a tetratricopeptide repeat (TPR) domain (Smith 2004). The TPR co-chaperones include two members of the FK506binding family of immunophilins FKBP52 and FKBP51, a member of the cyclosporin-binding immunophilin family cyclophilin 40, and the protein phosphatase PP5. FKBP52, FKBP51, and cyclophilin 40 are peptidylprolyl isomerases (PPlase), and they can influence conformation of protein substrates. While roles for HSPs in initiating and maintaining receptor competency for hormone binding are well documented, less is known about the contribution of other co-chaperones in receptor complexes. There is evidence that FKBP52 potentiates the function of glucocorticoid receptors (Riggs et al. 2003, Davies \& Sanchez 2005, Wochnik et al. 2005), progesterone receptors (PR; Tranguch et al. 2005), and androgen receptors (AR; Cheung-Flynn et al. 2005). Although several studies suggest that FKBP52 plays a role in nuclear transport of receptor complexes, 
it is not clear whether this role is physiologically critical (Riggs et al. 2003, Cheung-Flynn et al. 2005, Davies \& Sanchez 2005).

The infertility phenotype of both Fkbp52 null male and female mice on a C57BL/6/129 background demonstrates the critical function of this immunophilin co-chaperone in reproductive processes (Cheung-Flynn et al. 2005, Tranguch et al. 2005). We have recently shown that FKBP52 is a critical co-chaperone for uterine $\mathrm{PR}$ function during early pregnancy, and females missing the Fkbp52 gene show implantation failure (Tranguch et al. 2005). Fkbp52 null males exhibit numerous reproductive defects consistent with androgen insensitivity, including ambiguous external genitalia and dysgenic prostate (Cheung-Flynn et al. 2005). This is consistent with the findings that FKBP52 enhances AR-mediated transactivation in cellular models (Cheung-Flynn et al. 2005), and the loss of this FKBP52-enhancing activity accounts for major phenotypic features in Fkbp52 null males. While FKBP52 is expressed in most cell types in wild-type testes, testicular histology and spermatogenesis appear normal in null males (Cheung-Flynn et al. 2005). The abnormal external genital morphology of Fkbp52 null males prevents successful copulation; therefore, fertilization capacity has not yet been investigated in this mouse model. Here, we show that male mice missing FKBP52 on both C57BL/6/129 and CD1 backgrounds have abnormal sperm morphology and reduced capacity to fertilize wild-type oocytes.

\section{Materials and Methods}

\section{Animals}

The disruption of the Fkbp52 gene was achieved by homologous recombination as described previously (Cheung-Flynn et al. 2005). Tail genomic DNA was used for genotyping by PCR. Experiments were conducted on Fkbp52 $2^{+1+}$ and $F k b p 52^{-1-}$ males on each genetic background (C57BL/6/129 and CD1) between 12 and 16 weeks of age. We introduced Fkbp52 deficiency in CD1 mice by crossing with C57BL/6/129 Fkbp52 ${ }^{+1-}$ mice. In brief, C57BL/6/129 Fkbp52 ${ }^{+/-}$ females were crossed to CD1 wild-type males producing an F1 generation. F1 Fkbp52 $2^{+/-}$females were then backcrossed to CD1 wild-type males, and the process was continued for ten generations. All mice were housed in accordance with the National Institutes of Health (NIH) and Institutional guidelines on the care and use of laboratory animals.

\section{In situ hybridization}

In situ hybridization was performed as described previously by us (Das et al. 1994). In brief, frozen sections $(10 \mu \mathrm{m})$ were mounted onto poly-L-lysine coated slides and fixed in $4 \%$ paraformaldehyde in PBS. The sections were prehybridized and hybridized at $45{ }^{\circ} \mathrm{C}$ for $4 \mathrm{~h}$ in $50 \%$ formamide hybridization buffer containing ${ }^{35} \mathrm{~S}$-labeled antisense or sense cRNA probes. Probes had specific activities of approximately

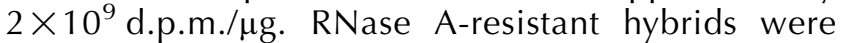
detected by autoradiography. Sections were post-stained with hematoxylin and eosin. Sections hybridized with sense probes showed no positive signal and served as negative controls.

\section{Immunohistochemical staining}

Immunolocalization of AR and FKBP52 was performed in Bouin's fixed paraffin-embedded sections as described previously (Cheung-Flynn et al. 2005, Daikoku et al. 2005).

\section{Indirect immunofluorescence}

Epididymal sperm were fixed on glass slides in $2 \%$ paraformaldehyde on ice. After washing, they were incubated in 8\% BSA at room temperature for $1 \mathrm{~h}$, exposed to FKBP52 antibody (1:200, custom-made) or propidium iodide (PI; $10 \mu \mathrm{g} / \mathrm{ml}$; Sigma) for $16 \mathrm{~h}$ at $4{ }^{\circ} \mathrm{C}$, washed and incubated with fluorescein isothiocyanate (FITC)conjugated affinity purified donkey anti-rabbit $\lg \mathrm{G}$ (FKBP52; 1:200; Jackson ImmunoResearch, West Grove, $\mathrm{PA}$, USA) for $1 \mathrm{~h}$. Signals were captured under a fluorescent microscope (Nikon Microsystems, Melville, NY, USA).

\section{Semi-quantitative RT-PCR}

Total RNA was extracted from whole epididymis or individually from isolated caput, corpus, and cauda of wild-type and Fkbp52 null mice using Trizol reagent according to the manufacturer's instructions. RT with oligo dT primers was performed to generate cDNAs from $5 \mu \mathrm{g}$ total RNA using Superscript II. DNA amplification was carried out with Taq DNA polymerase (Invitrogen) using the following primers: Fkbp51 (403 bp), 5'-AAGGTGTTGGCAGTCAATCC-3' , and 5'-GGTGGT CATTTGGGAAGCTA-3'; Adam7 (363 bp), 5'-GGTCATT GTGCTTGTCATGC-3', and 5'-ACGGAGGATAGCCCA GTCT-3'; Gpx5 (339 bp), 5'-AGCCAGCTATGTGCAG ACAA-3', and 5'-AACCCTTTTCCTGGACGAAC-3'; carbonic anhydrase 2 (Car2; 378 bp), 5'-ACCACT GGGGATACAGCAAG-3', and 5'-CCCCATATTTGGT GTTCCAG-3'; Serpine2 (357 bp), 5'-GGGATCCAGGTC TTCAATCA- ${ }^{\prime}$, and $5^{\prime}$-GATGGACTCAGAGGCAGAGG- ${ }^{\prime}$; $r P L 7$ (246 bp), 5' ${ }^{\prime}$-TCAATGGAGTAAGCCCAAAG- ${ }^{\prime}$, and 5'-CAAGAGACCGAGCAATCAAG-3'. PCR conditions were $95^{\circ} \mathrm{C}$ for $5 \mathrm{~min}$ and then 35 cycles of $94{ }^{\circ} \mathrm{C}$ for $30 \mathrm{~s}, 60^{\circ} \mathrm{C}$ for $30 \mathrm{~s}$, and $72{ }^{\circ} \mathrm{C}$ for $45 \mathrm{~s}$, followed by incubation at $72{ }^{\circ} \mathrm{C}$ for $10 \mathrm{~min}$. Amplified fragments were separated by electrophoresis on $2 \%$ agarose gels 
and visualized by ethidium bromide staining. The intensity of each band was measured by Scion Image (Scion Corp., Maryland, USA), and signals for Fkbp51, Adam7, Gpx5, Car2, and Serpine2 were evaluated by comparing against the intensity of a house-keeping gene $r P L 7$.

\section{Western blot analysis}

Sperm $\left(\sim 10^{6}\right.$ cells) were isolated from the epididymis of mature wild-type males and thoroughly washed in PBS. Sperm were then pelleted by centrifugation at $3300 \mathrm{~g}$ for $5 \mathrm{~min}$ and resuspended in $250 \mu \mathrm{l}$ SDS sample buffer. Supernatants were boiled for $5 \mathrm{~min}$ in SDS sample buffer containing $\beta$-mercaptoethanol, run on $10 \%$ SDS-PAGE gels under reducing conditions and transferred onto nitrocellulose membranes. Membranes were blocked with $10 \%$ milk in Tris-buffered saline-Tween 20 (TBST) for $1 \mathrm{~h}$ at room temperature and then incubated in 1\% milk containing anti-FKBP52 antibodies (1:5000) or antiactin antibodies (1:500; Invitrogen) overnight at $4{ }^{\circ} \mathrm{C}$. After incubation, membranes were washed thrice (15 min each) with TBST, incubated with goat anti-rabbit (FKBP52) or rabbit anti-goat (actin) IgG conjugated with horseradish peroxidase (1:10 000; Invitrogen) in 1\% milk at room temperature, and washed thrice (15 min each) with TBST. The bands were detected using an enhanced luminescence kit (Amersham Pharmacia Biotech).

\section{Sperm counts}

Epididymis were isolated from mature $\mathrm{Fkbp52}^{+/+}$or Fkbp52 $2^{-1-}$ males and placed into $500 \mu$ l preincubated human tubal fluid (HTF) medium (Specialty Media, Phillipsburg, NJ, USA). Sperm were collected by teasing the whole epididymis, and aliquots $(20 \mu \mathrm{l})$ of a 1:10 dilution of this whole epididymal sperm suspension were counted using a hemocytometer. For morphological analysis, sperm were collected from each respective epididymal region and placed into HTF medium for $10 \mathrm{~min}$ at $37^{\circ} \mathrm{C}$ for morphology observation under phase contrast microscopy.

\section{Acrosome reaction}

Sperm isolated from $\mathrm{Fkbp52}+/+$ and $\mathrm{Fkbp}_{52} \mathrm{2}^{-/-}$cauda epididymis were capacitated for $1.5 \mathrm{~h}$ followed by 5 -min incubation in $10 \mu \mathrm{M}$ calcium ionophore A23187 (Sigma). Dimethylsulfoxide (0.01\%) was used to dissolve the ionophore and served as a vehicle control. Sperm were fixed in ice-cold $100 \%$ ethanol, air-dried onto poly-L-lysine coated slides, and labeled with tetramethylrhodamine isothiocyanate (FITC)-conjugated Arachis hypogaea lectin $(0.5 \mathrm{mg} / \mathrm{ml}$ in PBS, Sigma) at room temperature for $20 \mathrm{~min}$, washed and mounted. Sperm were scored based on acrosomal reaction.

\section{In vitro fertilization}

In vitro fertilization was performed as described previously by us (Matsumoto et al. 2001). Briefly, wildtype C57BL/6/129 or CD1 female mice were superovulated by i.p. injections of $5 \mathrm{IU}$ pregnant mare serum gonadotropin (Sigma) followed by injections of $5 \mathrm{IU}$ human chorionic gonadotropin (hCG, Sigma) $48 \mathrm{~h}$ later. Cumulus-oocyte complexes were collected from the oviduct ampulla 12-14 h post-hCG injection and placed in $100 \mu \mathrm{l}$ droplets of HTF medium (Chemicon, Temecula, CA, USA). Sperm were collected from whole epididymis of 8-12-week-old Fkbp52 $2^{+/+}$or Fkbp52 males on C57BL/6/129 or CD1 backgrounds and placed in $400 \mu \mathrm{l} \mathrm{HTF}$ medium to allow capacitation for $2.5 \mathrm{~h}$ in a humidified $5 \% \mathrm{CO}_{2}$ incubator at $37^{\circ} \mathrm{C}$. Sperm $(\sim 1.2-$ $1.5 \times 10^{6} \mathrm{sperm} / \mathrm{ml}$ ) were then co-incubated with oocytes to allow fertilization to occur. After $6 \mathrm{~h}$, sperm were removed and putative zygotes placed in $30 \mu \mathrm{l}$ drops of KSOM (potassium simplex optimized medium; Chemicon) and incubated in a humidified 5\% $\mathrm{CO}_{2}$ incubator at $37^{\circ} \mathrm{C}$. The cleavage rate (two-cell stage) at $24 \mathrm{~h}$ was used as an index of fertilization. Formation of two-cell embryos to blastocysts at $120 \mathrm{~h}$ indicated the developmental potential of the fertilized embryos.

\section{Results \\ FKBP52 is expressed in wild-type epididymis}

For spermatozoa to become completely mature, they must pass through the epididymis, beginning their maturation process in the caput and finalizing maturation in the cauda region (Mathieu et al. 1992). The epididymis is responsive to androgen which helps to mature and concentrate spermatozoa, convert testosterone to $5 \alpha$-dihydrotestosterone and to store spermatozoa (Inano et al. 1969, Setchell et al. 1993, Toshimori 2003). It has recently been shown that $F k b p 52^{-1-}$ males on a C57BL/6/129 background are infertile due to partial androgen insensitivity with ambiguous external genitalia, implying a role for FKBP52 in mediating functions of androgen-responsive tissues (Cheung-Flynn et al. 2005). FKBP52 expression has been detected in most spermatogenic cells of wild-type testes (Cheung-Flynn et al. 2005), but its expression has not yet been examined in the epididymis. To determine the cell specific expression of FKBP52 in wild-type epididymis, in situ hybridization and immunohistochemistry were performed. In situ hybridization detected Fkbp52 expression in epithelial cells of the initial segment (IS), caput, corpus, and cauda regions of the epididymis (Fig. 1A), albeit at low levels in the cauda. Localization of FKBP52 protein in similar cell types and regions confirms that the mRNA is effectively translated in the epididymis (Fig. 1B). FKBP52 protein was not detected in corresponding tissues of $F k b p 52^{-/-}$ mice (data not shown). 


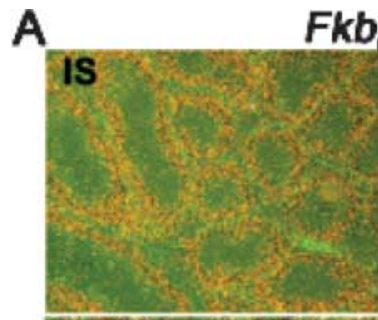

Fkbp52
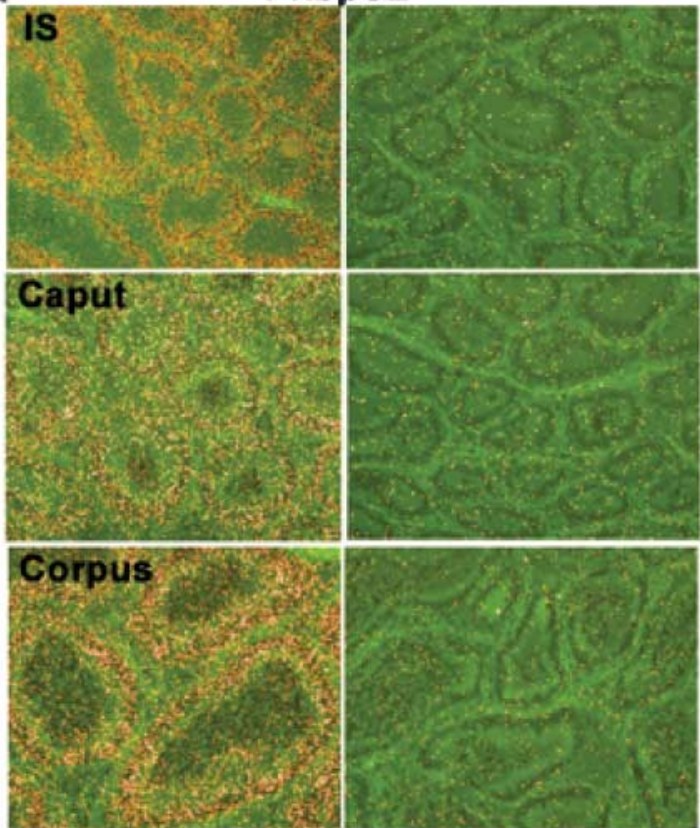

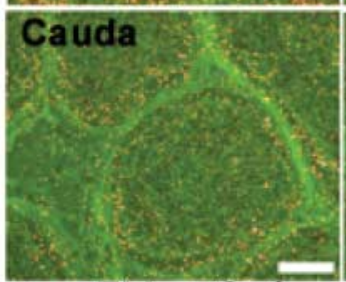

Fkbp52+/+
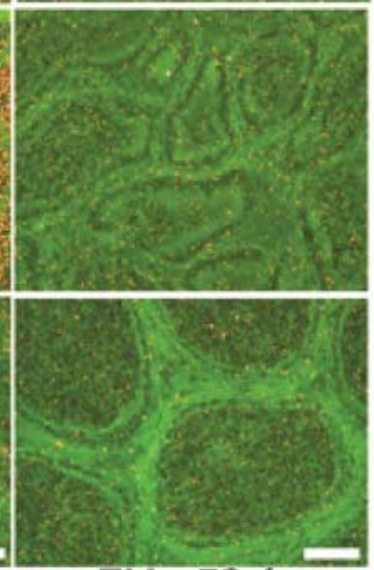

Fkbp52-\%
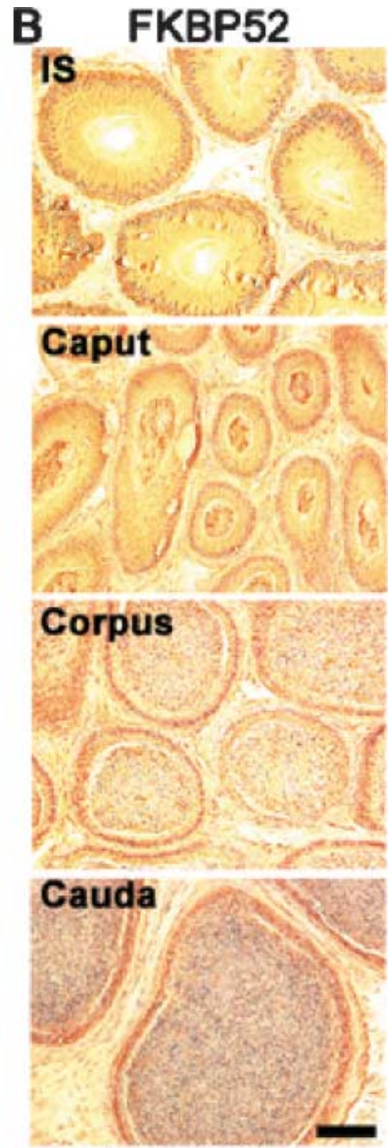

Fkbp52+/+
Figure 1 Expression of FKBP52 in the epididymis. (A) In situ hybridization of Fkbp52 in different regions of the epididymis in wild-type and $F k b p 52^{-1-}$ mice was compared. Darkfield photomicrographs of representative sections of wild-type and Fkbp52-1- epididymis are shown (bar, $200 \mu \mathrm{m}$ ). (B) Immunolocalization of FKBP52 in wild-type epididymis. Brightfield photomicrographs of representative sections of wild-type epididymis are shown (bar, $100 \mu \mathrm{m})$. Red color depicts positive signals. IS, initial segment.

\section{$A R$ expression is normal in Fkbp52 null epididymis}

FKBP52 is a known component of functionally mature steroid receptor complexes and potentiates AR function (Cheung-Flynn et al. 2005). Since immunostaining previously showed that AR expression is similar between wild-type and null testes (Cheung-Flynn et al. 2005), we compared AR expression in epididymis of wild-type versus Fkbp52 ${ }^{-1-}$ males. The pattern of AR localization in the epididymis was similar between wild-type and Fkbp52 $2^{-1-}$ mice. Specifically, AR staining was detected in nuclei of epithelial cells of the IS, caput, corpus, and cauda epididymis, showing that loss of FKBP52 does not alter AR expression or nuclear localization (Fig. 2A).

\section{Androgen-responsive genes are normally expressed in Fkbp52 null epididymis}

We have recently shown that $F k b p 52^{-1-}$ females with compromised PR function maintain normal levels of PR (Tranguch et al. 2005), confirming FKBP52's role in determining PR activity rather than affecting its expression levels. Our finding of normal AR expression in Fkbp52 epididymis suggests that FKBP52 is not required for accumulation or nuclear localization of $A R$, but is critical for receptor activity. If $A R$ functions are compromised in
Fkbp52 ${ }^{-1-}$ epididymis, then androgen-regulated genes would be aberrantly expressed. We selected androgenregulated genes that encode a disintegrin metalloprotease 7 (Adam7; Cornwall \& Hsia 1997), glutathione peroxidase 5 (Gpx5; Schwaab et al. 1998), Car2 (Kaunisto et al. 1999), and Serpine2 (Vassalli et al. 1993). Whereas Adam7 has been previously characterized as an androgen-regulated gene in the epididymis (Zwain et al. 1992, Cornwall \& Hsia 1997), Gpx5, Car2, and Serpine2 are androgen-regulated genes expressed specifically in the caput, corpus, and cauda respectively (Chauvin \& Griswold 2004). The whole epididymis, and the caput, corpus, and cauda regions were isolated from wild-type and Fkbp52 ${ }^{-1-}$ males. Semiquantitative RT-PCR shows that the expression of Adam7, Gpx5, Car2, and Serpine2 is similar between wild-type and $F k b p 52^{-1-}$ males in the whole epididymis or in specific epididymal regions (Fig. $2 \mathrm{~B}$ and $\mathrm{C}$ and data not shown). We compared the levels of these genes with a housekeeping gene $r P L 7$ run under the same condition.

FKBP52 and FKBP51 compete for a common binding site on HSP and thus for assembly with steroid receptor complexes (Riggs et al. 2003). Furthermore, FKBP51 has been shown to antagonize the action of FKBP52 on steroid hormone receptor function (Riggs et al. 2003). It is surprising that functional differences exist between 
A

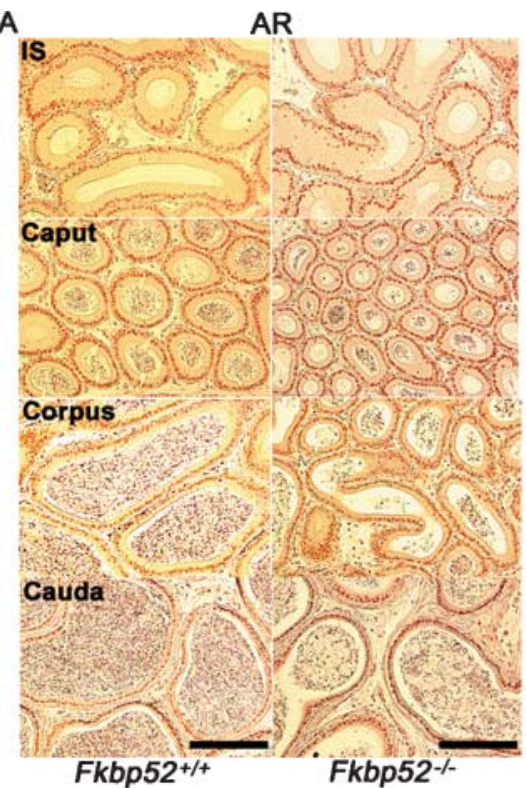

B
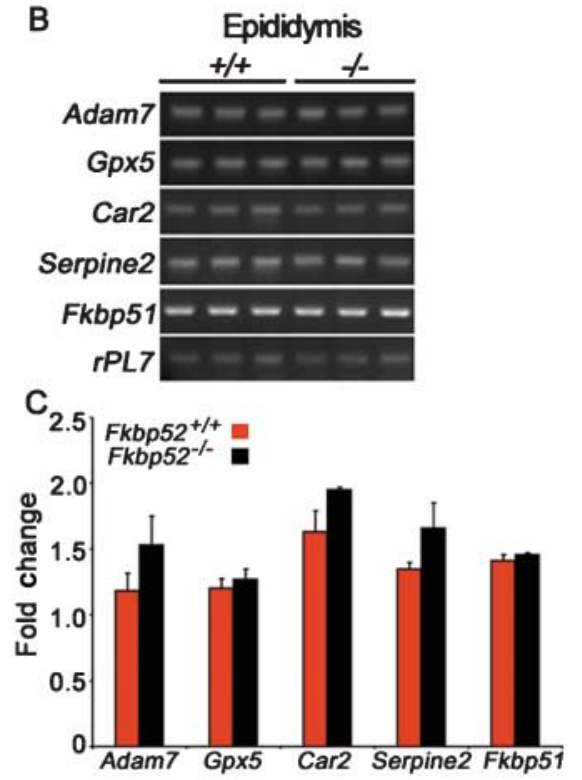

Figure 2 Immunolocalization of androgen receptor (AR) and expression of androgenregulated epididymal genes in $F k b p 52^{+/+}$ and $F k_{b p 52^{-1-}}$ males. (A) AR immunolocalization in wild-type and $F k b p 52^{-1-}$ epididymis. Brightfield photomicrographs of representative sections of wild-type and Fkbp52 ${ }^{-1-}$ epididymis are shown (bar, $200 \mu \mathrm{m}$ ). IS, initial segment. (B) Semiquantitative comparative RT-PCR of androgen-regulated genes (Adam7, Gpx5, Car2, Serpine) and Fkbp51 in wild-type and Fkbp52 ${ }^{-1-}$ mice. $r P L 7$ is a housekeeping gene. (C) RT-PCR data are presented as fold changes (mean \pm s.D.) of three independent RNA samples ( $P>0.05$; unpaired $t$-test). these two immunophilins given the $70 \%$ homology in their amino acid sequences (Nair et al. 1997). For example, while the infertile phenotype of Fkbp52 null males implicates its important role in fertility, Fkbp51 null males apparently do not display any reproductive defects (Cheung-Flynn et al. 2005). To determine whether Fkbp51 is overexpressed in Fkbp52 ${ }^{-1-}$ males to produce the observed infertility phenotype, we used comparative RT-PCR and found that Fkbp51 expression is not altered in Fkbp52 ${ }^{-1-}$ epididymis (Fig. 2B and C). These results indicate that the infertile phenotype observed in $F k b p 52^{-1-}$ males is specific to Fkbp52 deficiency, and not due to aberrant expression of Fkbp51.

\section{FKBP52 plays a role in governing sperm morphology}

We observed FKBP52 presence in spermatozoa of wildtype epididymis (Fig. 1A and B). This observation was further confirmed by western blotting detection of FKBP52 protein in sperm isolated from wild-type epididymis (Fig. 3A). To determine FKBP52 localization in wild-type sperm, we performed indirect immunofluorescence and found its expression specifically in the acrosome of sperm, and in the midpiece and annulus of sperm tails (Fig. 3B). The annulus is located at the distal end of the midpiece and is thought to serve as a stabilizing structure for tail rigidity (Cesario \& Bartles 1994). Indeed, annulus-deficient sperm have been shown to exhibit an abnormal bent morphology (Kissel et al. 2005). A similar bent morphology is observed in Fkbp52 $2^{-1-}$ sperm (Fig. 4A). In fact, almost $40 \%$ of cauda epididymal sperm had abnormal flagella morphology, forming hairpin bends (Fig. 4B). Sperm isolated from the caput and corpus regions of the epididymis, however, did not show abnormal morphology (Fig. 4B).

\section{Fkbp52 null sperm exhibit reduced fertilization capacity}

To address whether spermatogenesis occurs normally in Fkbp52 $2^{-1-}$ males, sperm were collected from wild-type and $F k b p 52^{-1-}$ epididymis and counted. The number of sperm collected from the whole epididymis was significantly lower in Fkbp52 $2^{-/-}$males when compared with wild-type littermates on both genetic backgrounds (Fig. 4C). This observation was not surprising since androgen receptor signaling is known to govern maintenance of spermatogenesis (Keller et al. 1996, Roy et al. 1999, Heinlein \& Chang 2002). To address whether inherent defects in sperm also contribute to male infertility, we first selected $F k b p 52^{-1-}$ males with minimal penile dysgenesis for breeding with wild-type females. However, we failed to detect any vaginal plugs from these breedings (data not shown). This may suggest poor mating activity of Fkbp52 $2^{-1-}$ males. We then sought to determine whether $F k b p 52^{-1-}$ sperm are capable of fertilizing wild-type oocytes. We performed in vitro fertilization using isolated sperm from $\mathrm{Fkbp52}^{-1-}$ males on either $\mathrm{C} 57 \mathrm{BL} / 6 / 129$ or CD1 background with eggs isolated from wild-type females on the same genetic background respectively. Sperm isolated from wild-type C57BL/6/129 males exhibited a $76 \%$ fertilization rate with wild-type eggs with $91 \%$ of fertilized embryos developing to the blastocyst stage (Fig. 5A and B). On the other hand, sperm isolated from C57BL/6/129 Fkbp52-/- males showed a markedly reduced fertilization rate (44\%). However, $88 \%$ of those fertilized embryos developed to the blastocyst stage which is comparable with rates seen for embryos fertilized by wild-type sperm (Fig. 5A and B).

There is increasing evidence that mutation of a gene often results in substantially altered phenotypes 

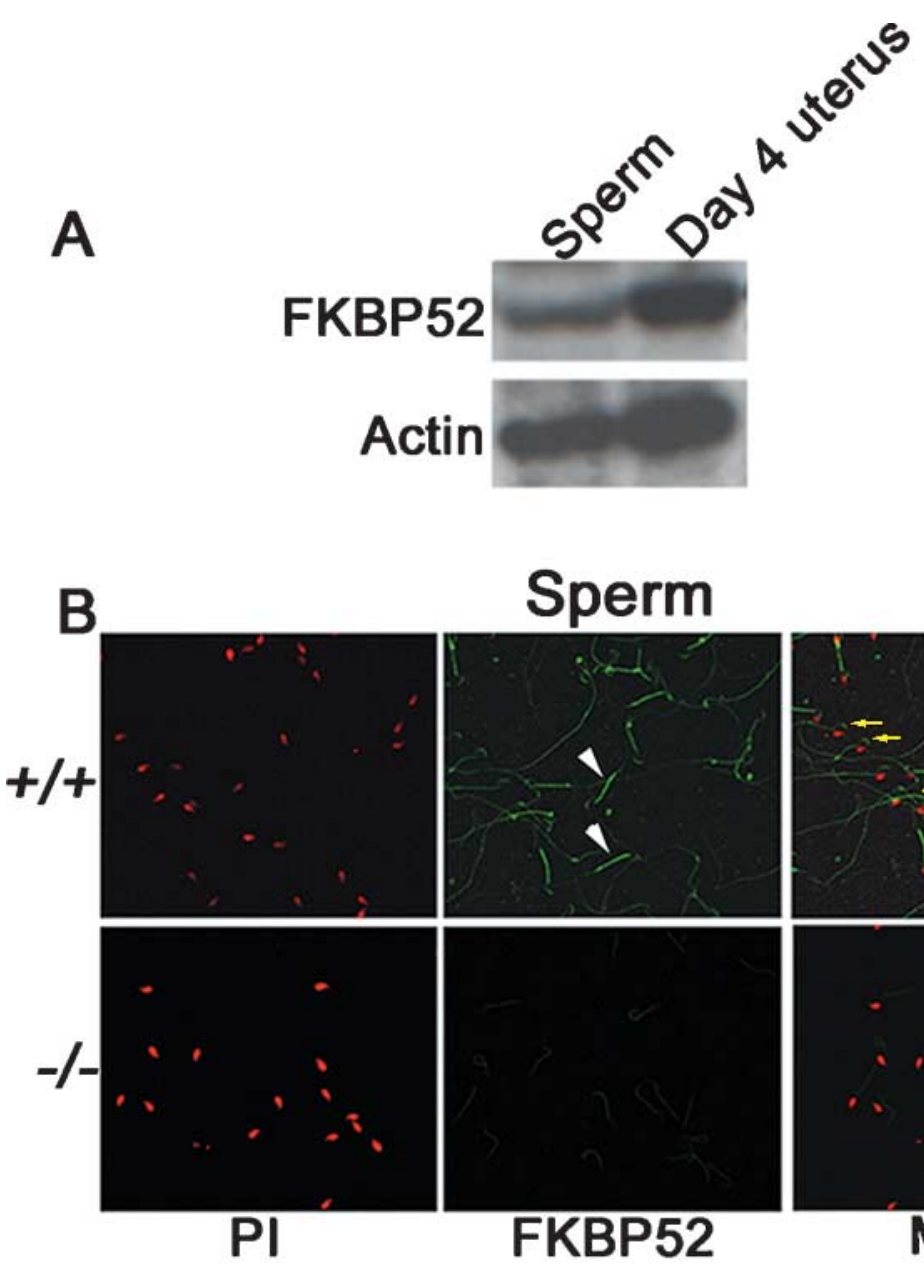

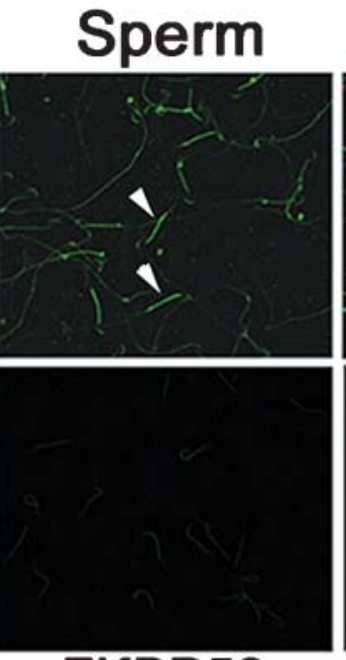

FKBP52
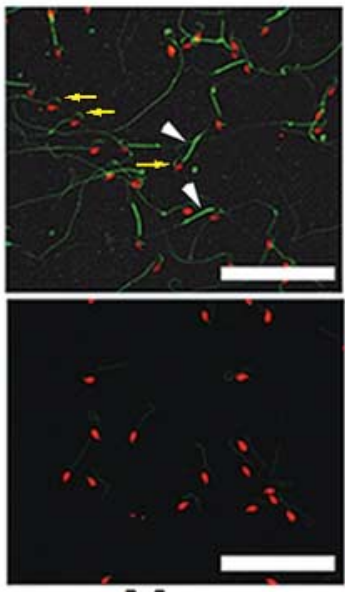

Merge
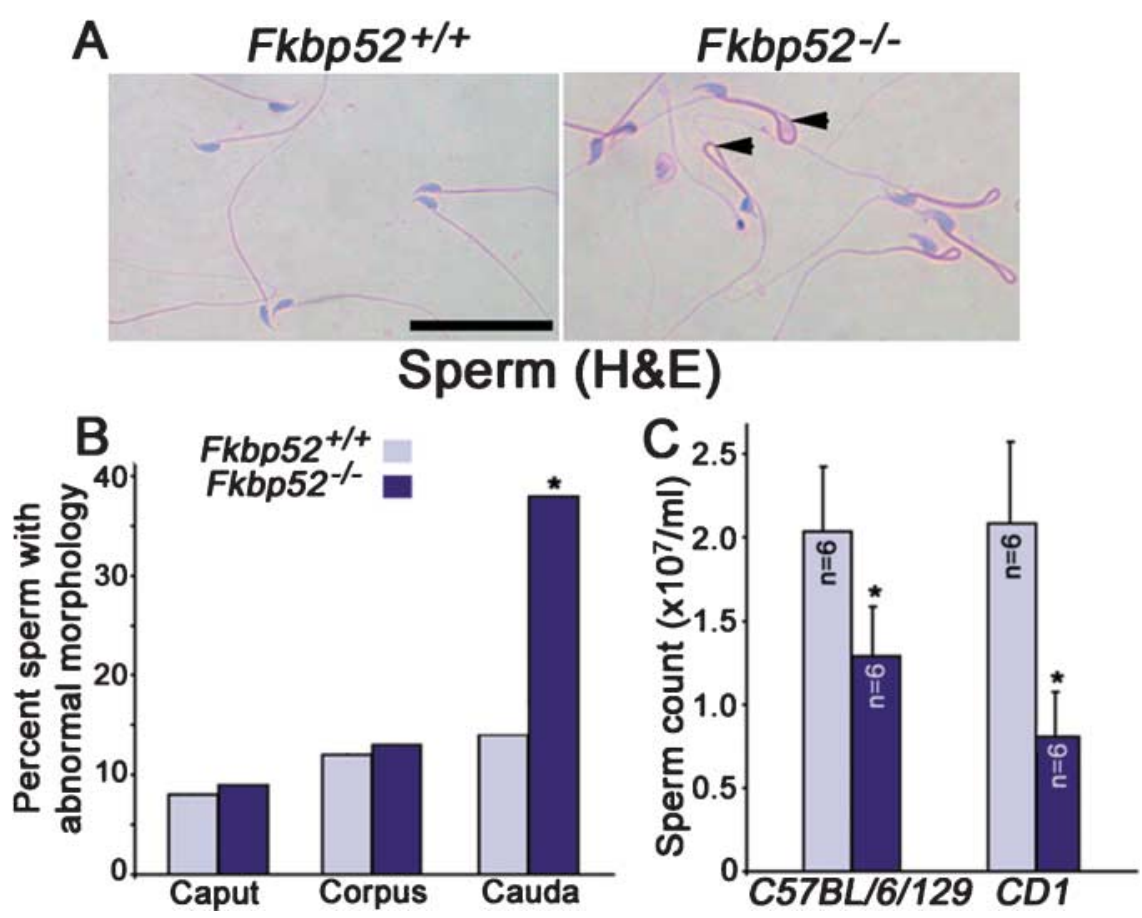

Figure 3 Expression of FKBP52 in sperm. (A) Western blot analysis of FKBP52 in wildtype epididymal sperm. Pregnant day-4 uterus served as a positive control. Actin is a housekeeping protein. (B) Indirect immunofluorescence of wild-type and Fkbp52-1sperm with anti-FKBP52 (FITC, green) antibodies. Sperm head DNA was stained with propidium iodide ( $\mathrm{PI}$; red). While white arrowheads denote FKBP52 localization specifically in the midpiece and annulus of sperm tails, yellow arrows denote FKBP52 localization in the sperm acrosome (bar, $100 \mu \mathrm{m}$ ).

Figure 4 Sperm morphology in wild-type versus Fkbp52 ${ }^{-1-}$ mice. (A) Sperm isolated from the cauda epididymis were stained with hematoxylin and eosin. A representative brightfield photomicrograph is shown (bar, $100 \mu \mathrm{m}$ ). Arrowheads denote hairpin bends frequently observed in sperm of Fkbp52 $^{-1-}$ males. (B) Sperm morphology was analyzed from the caput, corpus, and caudal regions of wild-type and Fkbp52 ${ }^{-/-}$ epididymis. Abnormal sperm morphology (hairpin bends) in $\mathrm{Fkbp52}^{-1-}$ males was only observed in sperm isolated from the cauda epididymis $(* P<0.01$; unpaired $t$-test). Data are presented from $20\left(F k b p 52^{+/+}\right)$ and $22\left(\right.$ Fkbp52 $\left.2^{-I}\right)$ independent samples. (C) Sperm count is significantly lower in Fkbp52 $2^{-1-}$ epididymis when compared with wild-type males $\left({ }^{*} P<0.05\right.$; unpaired $t$-test). Data are presented from $6 \mathrm{Fkbp} 52^{+}$ ${ }^{1+}$ and $\mathrm{Fkbp52} 2^{-1-}$ male mice on each genetic background. 

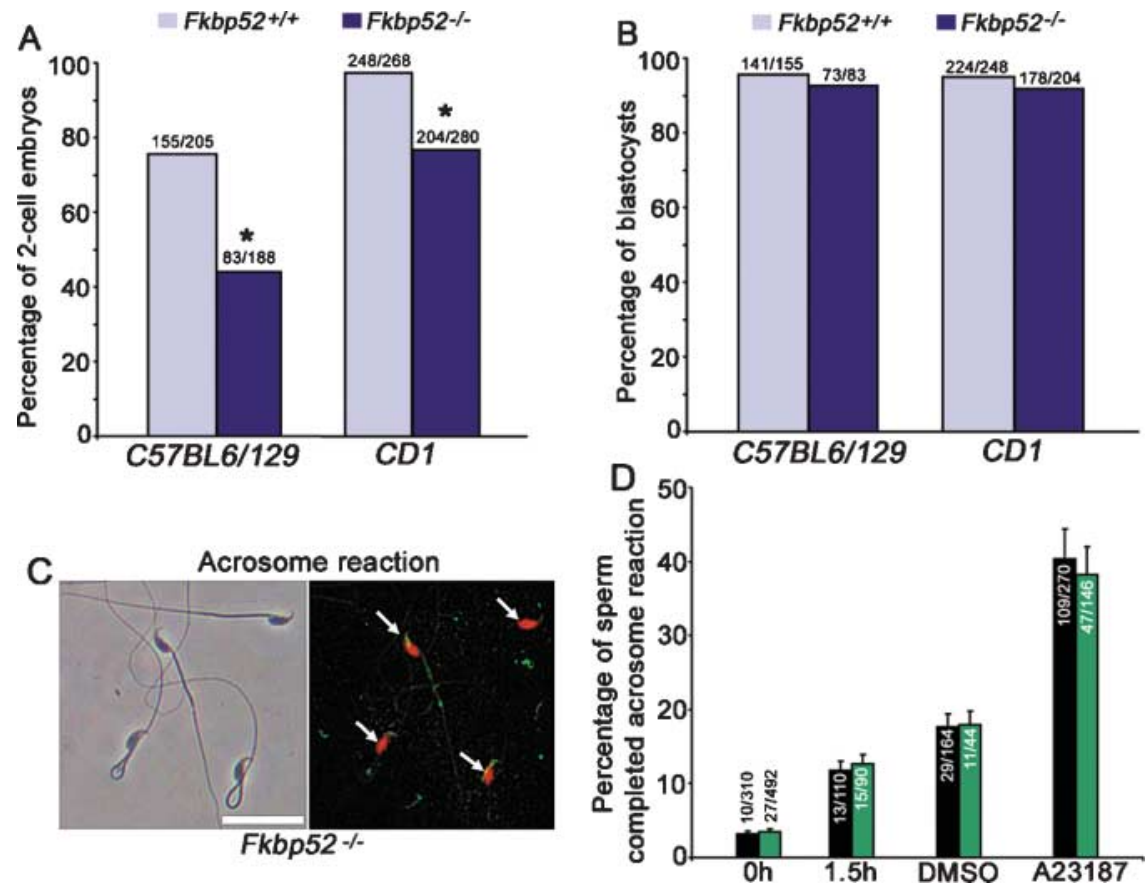

Figure 5 In vitro fertilizing capacity of wild-type and $F k b p 52^{-/-}$sperm. (A) Percentage of wild-type oocytes fertilized by wild-type or $F k b p 52^{-/-}$ sperm on either C57BL/6/129 or CD1 background. Fertilizing capacity of $F k b p 52^{-/-}$sperm is significantly lower than wild-type sperm $\left(^{*} P<0.01\right.$; $\chi^{2}$-analysis). Numbers above bars indicate the sum of number of fertilized oocytes/total oocytes for all three experiments. (B) Percentage of fertilized embryos (two-cell) resulting from wild-type and $F k b p 52^{-1-}$ sperm that developed to blastocysts. No difference was observed between wild-type and Fkbp52 $2^{-1-}$ mice on either genetic background. Numbers above bars indicate the sum of fertilized oocytes developed to the blastocyst stage/total fertilized oocytes for all three experiments. For each experiment, two males of each genotype were used, and oocytes were collected from eight CD1 or ten C57BL/6/129 wild-type females. Each experiment was performed thrice. (C) In vitro acrosome reaction of caudal epididymal sperm from wildtype and $F k b p 52^{-1-}$ males. Representative brightfield (left panel) and darkfield (right panel) photomicrographs of sperm isolated from $F k b p 52^{-/-}$ males (bar, $100 \mu \mathrm{m})$. The acrosome reaction is denoted by green staining of FITC-conjugated Arachis hypogaea lectin. Arrows denote sperm that completed the acrosome reaction. Sperm heads were stained using propidium iodide (red). (D) The percentage of sperm showing acrosome reaction was comparable between wild-type and $F k b p 52^{-1-}$ males $(P>0.05$; unpaired $t$-test). $0 \mathrm{~h}$, sperm without incubation/treatment; $1.5 \mathrm{~h}$, incubation at $37^{\circ} \mathrm{C}$ post-extraction; DMSO, incubation at $37^{\circ} \mathrm{C}$ post-extraction $(1.5 \mathrm{~h})+\mathrm{DMSO}$ treatment $(0.01 \%) ; \mathrm{A} 23187$, incubation at $37^{\circ} \mathrm{C}$ post-extraction $(1.5 \mathrm{~h})+$ calcium ionophore $(10 \mu \mathrm{M})$. DMSO was used to dissolve the calcium ionophore A23187. Experiments were performed in triplicate. Numbers above $(0 \mathrm{~h})$ and within bars indicate acrosome-reacted sperm/total sperm.

depending on the genetic background of mice in which the mutation is maintained. It was previously noted that abnormalities in sexual development, including external and internal genitalia, in Fkbp52 null males on both C57BL/6/129 and CD1 background is similar (CheungFlynn et al. 2005). Similar to C57BL/6/129 Fkbp52 ${ }^{-9-}$ males as described earlier, we found that CD1 Fkbp52 $2^{-1-}$ males bred with wild-type females failed to produce vaginal plugs (data not shown). In fact, the infertility phenotype was maintained in CD1 Fkbp52 ${ }^{-1-}$ males. This prompted us to examine the fertilizing capacity of sperm from CD1 Fkbp52 ${ }^{-/-}$mice in vitro. We found that sperm isolated from wild-type CD1 males show normal fertilization (93\%) of wild-type eggs with $90 \%$ of fertilized embryos developing to blastocysts (Fig. 5A and B). In contrast, sperm isolated from CD1 Fkbp52 ${ }^{-1-}$ males again showed compromised fertilization rate $(73 \%)$, although development of fertilized embryos to blastocysts proceeded normally; $88 \%$ of two-cell embryos developed to blastocysts (Fig. 5A and B). The in vitro fertilizing capacity of sperm from CD1 $\mathrm{Fkbp52} \mathrm{2}^{-/-}$males was not as dramatic as that of $\mathrm{C} 57 \mathrm{BL} / 6 / 129 \mathrm{Fkbp52} 2^{-1-}$ males. This is not unexpected, since outbred CD1 mice have more robust reproduction than those on a $\mathrm{C} 57 \mathrm{BL} / 6 / 129$ background. The observed reduction in fertilization capacity in Fkbp52 null mice on both genetic backgrounds provides convincing evidence for a role for FKBP52 in fertilization.

It is known that the failure of the acrosome reaction can contribute to sperm's fertilization capacity (Sabeur et al. 1996). Because of our observation of FKBP52 localization in sperm acrosome (Fig. 3B), we tested whether the acrosome reaction occurs normally in Fkbp52 $2^{-1-}$ sperm by examining the response of wildtype and Fkbp52 null sperm to a calcium ionophore A23187. No significant differences in the induction of acrosome reaction were noted between wild-type and Fkbp52 ${ }^{-1-}$ sperm (Fig. 5C and D), suggesting an alternative role for FKBP52 in mediating spermegg interactions. 


\section{Discussion}

Although FKBP52 is expressed in a wide variety of vertebrate tissues (Peattie et al. 1992, Nair et al. 1997),

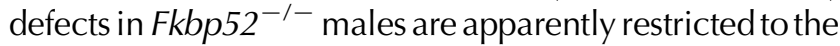
reproductive organs (Cheung-Flynn et al. 2005). The reproductive phenotype of $F k b p 52$ null male mice results from partial androgen insensitivity in a selected number of reproductive organs, specifically the anterior prostate and external genitalia (Cheung-Flynn et al. 2005). While the epididymis is an androgen-responsive tissue, the finding of normal development of the epididymis and expression of androgen-regulated genes in the epididymis in Fkbp52 ${ }^{-/-}$ males is surprising. It is possible that locally high androgen levels in epididymal tissue lessen the need for FKBP52 in AR complexes (Cheung-Flynn et al. 2005). Nonetheless, our observations of localization of FKBP52 in wild-type spermatozoa and compromised in vitro fertilizing capacity of $F k b p 52^{-1-}$ sperm indicate a novel role for this immunophilin co-chaperone in sperm function.

Biogenesis of mammalian sperm tails begins early during spermatogenesis with the development of a primary flagellum, a simple axoneme enveloped by a plasma membrane (Irons \& Clermont 1982). Proteins involved in flagellar maturation are assumed to be synthesized in the spermatid cell body and transported down the axoneme to sites of assembly (Irons \& Clermont 1982). FKBP52 expression specifically in the midpiece and annulus of spermatozoa, and abnormal Fkbp52 $2^{-1-}$ sperm morphology implicates a role for FKBP52 in tail development and/or movement. FKBP52 binds to dynein, and evidence suggests direct binding to dynein through FKBP52's PPlase domain (Silverstein et al. 1999, Galigniana et al. 2001). FK506, an immunosuppressant drug, binds to the PPlase active site to block PPlase activity, although FKBP52 binding to dynein in vitro is not inhibited by FK506 (Silverstein et al. 1999). Still, FK506 has been shown to reduce sperm counts and motility in a rat model (Hisatomi et al. 1996), suggesting FKBP52-dynein interactions in vivo. Consistent with a possible role for FKBP52-dynein interactions in sperm flagella, mice lacking functional dynein heavy chain (Dnahc1) show severe asthenozoospermia (Neesen et al. 2001, Vernon et al. 2005). It is thus possible that FKBP52 functions independent of steroid receptor, perhaps interacting with dynein to govern flagella formation and/or maturation for successful fertilization.

Sperm-egg interactions involve binding of acrosomeintact spermatozoa to the zona pellucida, induction of the acrosome reaction, consequent binding of acrosomereacted sperm to the zona pellucida matrix, penetration through the matrix, and binding to the oocyte plasma membrane for sperm-oocyte fusion (Nixon et al. 2005). The role of chaperones and co-chaperones in sperm-egg recognition and interaction remains unclear. It has been shown that mammalian sperm express surface chaperones including endoplasmin, HSP60, HSP70, and HSP90 that each could play roles in interacting and binding to the zona pellucida (Bohring et al. 2001, Bohring \& Krause 2003, Ecroyd et al. 2003, Ficarro et al. 2003). FKBP52's classification as a HSP90-binding immunophilin and perhaps its ability to bind with other heat shock protein family members suggests a role for FKBP52 during these events. But the exact mechanism by which FKBP52 mediates sperm-egg interactions during fertilization remains to be determined. Recently, several rapid nongenomic effects of progesterone and estrogen have been described for human spermatozoa (Baldi et al. 1998, 2000). These effects include, among others, calcium influx, tyrosine phosphorylation of various substrates, and increased cAMP levels, all contributing to capacitation and hyperactivated motility of sperm (Baldi et al. 1998, Luconi et al. 2004). Whether FKBP52 participates in membrane steroid hormone receptor signaling remains to be determined. Nonetheless, the present study provides evidence for roles of FKBP52 in sperm morphology and fertilizing capacity. This presents a clinically relevant finding since FKBP52 can perhaps serve as a target for developing novel contraceptives and for treatment of male infertility.

\section{Acknowledgements}

We thank Hiromichi Matsumoto for his assistance with in vitro fertilization, Toshifumi Takahashi for assistance with immunofluorescence experiments and Fuhua Xu for help with statistical analysis. We also thank Carlos Suarez-Quian for critical reading of the manuscript. This work was supported in parts by NIH grants (HD 12304 and DA06668). ST is supported by NIH grant 5 T 32 DK07563. The authors declare that there is no conflict of interest that would prejudice the impartiality of this scientific work.

\section{References}

Baldi E, Luconi M, Bonaccorsi L \& Forti G 1998 Nongenomic effects of progesterone on spermatozoa: mechanisms of signal transduction and clinical implications. Frontiers in Bioscience 3 D1051-D1059.

Baldi E, Luconi M, Muratori M \& Forti G 2000 A novel functional estrogen receptor on human sperm membrane interferes with progesterone effects. Molecular and Cellular Endocrinology 161 31-35.

Bohring C \& Krause W 2003 Characterization of spermatozoa surface antigens by antisperm antibodies and its influence on acrosomal exocytosis. American Journal of Reproductive Immunology 50 411-419.

Bohring C, Krause E, Habermann B \& Krause W 2001 Isolation and identification of sperm membrane antigens recognized by antisperm antibodies, and their possible role in immunological infertility disease. Molecular Human Reproduction 7 113-118.

Cesario MM \& Bartles JR 1994 Compartmentalization, processing and redistribution of the plasma membrane protein CE9 on rodent spermatozoa. Relationship of the annulus to domain boundaries in the plasma membrane of the tail. Journal of Cell Science 107 561-570.

Chauvin TR \& Griswold MD 2004 Androgen-regulated genes in the murine epididymis. Biology of Reproduction 71 560-569.

Cheung-Flynn J, Prapapanich V, Cox MB, Riggs DL, Suarez-Quian C \& Smith DF 2005 Physiological role for the cochaperone FKBP52 in androgen receptor signaling. Molecular Endocrinology 19 1654-1666. 
Cornwall GA \& Hsia N 1997 ADAM7, a member of the ADAM (a disintegrin and metalloprotease) gene family is specifically expressed in the mouse anterior pituitary and epididymis. Endocrinology 138 4262-4272.

Daikoku T, Tranguch S, Friedman DB, Das SK, Smith DF \& Dey SK 2005 Proteomic analysis identifies immunophilin FK506 binding protein 4 (FKBP52) as a downstream target of Hoxa10 in the periimplantation mouse uterus. Molecular Endocrinology 19 683-697.

Das SK, Wang XN, Paria BC, Damm D, Abraham JA, Klagsbrun M, Andrews GK \& Dey SK 1994 Heparin-binding EGF-like growth factor gene is induced in the mouse uterus temporally by the blastocyst solely at the site of its apposition: a possible ligand for interaction with blastocyst EGF-receptor in implantation. Development 120 1071-1083.

Davies TH \& Sanchez ER 2005 Fkbp52. International Journal of Biochemistry \& Cell Biology 37 42-47.

Ecroyd H, Jones RJ \& Aitken RJ 2003 Tyrosine phosphorylation of HSP90 during mammalian sperm capacitation. Biology of Reproduction 69 1801-1807.

Ficarro S, Chertihin O, Westbrook VA, White F, Jayes F, Kalab P, Marto JA, Shabanowitz J, Herr JC, Hunt DF \& Visconti PE 2003 Phosphoproteome analysis of capacitated human sperm. Evidence of tyrosine phosphorylation of a kinase-anchoring protein 3 and valosin-containing protein/p97 during capacitation. Journal of Biological Chemistry 278 11579-11589.

Galigniana MD, Radanyi C, Renoir JM, Housley PR \& Pratt WB 2001 Evidence that the peptidylprolyl isomerase domain of the hsp90binding immunophilin FKBP52 is involved in both dynein interaction and glucocorticoid receptor movement to the nucleus. Journal of Biological Chemistry 276 14884-14889.

Heinlein CA \& Chang C 2002 Androgen receptor (AR) coregulators: an overview. Endocrine Reviews 23 175-200.

Hisatomi A, Fujihira S, Fujimoto Y, Fujii T, Mine Y \& Ohara K 1996 Effect of Prograf (FK506) on spermatogenesis in rats. Toxicology 109 75-83.

Inano H, Machino A \& Tamaoki B 1969 In vitro metabolism of steroid hormones by cell-free homogenates of epididymides of adult rats. Endocrinology 84 997-1003.

Irons MJ \& Clermont Y 1982 Kinetics of fibrous sheath formation in the rat spermatid. American Journal of Anatomy 165 121-130.

Kaunisto K, Fleming RE, Kneer J, Sly WS \& Rajaniemi H 1999 Regional expression and androgen regulation of carbonic anhydrase IV and II in the adult rat epididymis. Biology of Reproduction 61 1521-1526.

Keller ET, Ershler WB \& Chang C 1996 The androgen receptor: a mediator of diverse responses. Frontiers in Bioscience $\mathbf{1}$ d59-d71.

Kissel H, Georgescu MM, Larisch S, Manova K, Hunnicutt GR \& Steller $\mathbf{H} 2005$ The Sept4 septin locus is required for sperm terminal differentiation in mice. Developmental Cell 8 353-364.

Luconi M, Francavilla F, Porazzi I, Macerola B, Forti G \& Baldi E 2004 Human spermatozoa as a model for studying membrane receptors mediating rapid nongenomic effects of progesterone and estrogens. Steroids 69 553-559.

Mathieu C, Guerin JF, Cognat M, Lejeune H, Pinatel MC \& Lornage J 1992 Motility and fertilizing capacity of epididymal human spermatozoa in normal and pathological cases. Fertility and Sterility 57 871-876.

Matsumoto H, Ma W, Smalley W, Trzaskos J, Breyer RM \& Dey SK 2001 Diversification of cyclooxygenase-2-derived prostaglandins in ovulation and implantation. Biology of Reproduction 64 1557-1565.

Nair SC, Rimerman RA, Toran EJ, Chen S, Prapapanich V, Butts RN \& Smith DF 1997 Molecular cloning of human FKBP51 and comparisons of immunophilin interactions with Hsp90 and progesterone receptor. Molecular and Cellular Biology 17 594-603.

Neesen J, Kirschner R, Ochs M, Schmiedl A, Habermann B, Mueller C, Holstein AF, Nuesslein T, Adham I \& Engel W 2001 Disruption of an inner arm dynein heavy chain gene results in asthenozoospermia and reduced ciliary beat frequency. Human Molecular Genetics 10 1117-1128.
Nixon B, Asquith KL \& Aitken RJ 2005 The role of molecular chaperones in mouse sperm-egg interactions. Molecular and Cellular Endocrinology 240 1-10.

Orgebin-Crist MC 1967 Sperm maturation in rabbit epididymis. Nature $216816-818$.

Peattie DA, Harding MW, Fleming MA, DeCenzo MT, Lippke JA, Livingston DJ \& Benasutti M 1992 Expression and characterization of human FKBP52, an immunophilin that associates with the 90-kDa heat shock protein and is a component of steroid receptor complexes. PNAS 89 10974-10978.

Pratt WB \& Toft DO 2003 Regulation of signaling protein function and trafficking by the hsp90/hsp70-based chaperone machinery. Experimental Biology and Medicine 228 111-133.

Riggs DL, Roberts PJ, Chirillo SC, Cheung-Flynn J, Prapapanich V, Ratajczak T, Gaber R, Picard D \& Smith DF 2003 The Hsp90binding peptidylprolyl isomerase FKBP52 potentiates glucocorticoid signaling in vivo. EMBO Journal 22 1158-1167.

Robaire B \& Hermo L 2002 Efferent ducts and vas deferens: structure, functions and their regulation. In The Physiology of Reproduction, pp 999-1080. Eds E Knobil \& JD Neill. New York: Raven Press.

Roy AK, Lavrovsky Y, Song CS, Chen S, Jung MH, Velu NK, Bi BY \& Chatterjee B 1999 Regulation of androgen action. Vitamins and Hormones 55 309-352.

Sabeur K, Edwards DP \& Meizel S 1996 Human sperm plasma membrane progesterone receptor(s) and the acrosome reaction. Biology of Reproduction 54 993-1001.

Schwaab V, Faure J, Dufaure JP \& Drevet JR 1998 Gpx3: the plasmatype glutathione peroxidase is expressed under androgenic control in the mouse epididymis and vas deferens. Molecular Reproduction and Development 51 362-372.

Setchell BP, Sanchez-Partida LG \& Chairussyuhur A 1993 Epididymal constituents and related substances in the storage of spermatozoa: a review. Reproduction, Fertility, and Development 5 601-612.

Silverstein AM, Galigniana MD, Kanelakis KC, Radanyi C, Renoir JM \& Pratt WB 1999 Different regions of the immunophilin FKBP52 determine its association with the glucocorticoid receptor, hsp90, and cytoplasmic dynein. Journal of Biological Chemistry $27 \mathbf{4}$ 36980-36986.

Smith DF 2004 Tetratricopeptide repeat cochaperones in steroid receptor complexes. Cell Stress and Chaperones 9 109-121.

Toshimori K2003 Biology of spermatozoa maturation: an overview with an introduction to this issue. Microscopy Research and Technique 61 1-6.

Tranguch S, Cheung-Flynn J, Daikoku T, Prapapanich V, Cox MB, Xie H, Wang H, Das SK, Smith DF \& Dey SK 2005 Cochaperone immunophilin FKBP52 is critical to uterine receptivity for embryo implantation. PNAS 102 14326-14331.

Vassalli JD, Huarte J, Bosco D, Sappino AP, Sappino N, Velardi A, Wohlwend A, Erno H, Monard D \& Belin D 1993 Protease-nexin I as an androgen-dependent secretory product of the murine seminal vesicle. EMBO Journal 12 1871-1878.

Vernon GG, Neesen J \& Woolley DM 2005 Further studies on knockout mice lacking a functional dynein heavy chain (MDHC7)1. Evidence for a structural deficit in the axoneme. Cell Motility and the Cytoskeleton 61 65-73.

Wochnik GM, Ruegg J, Abel GA, Schmidt U, Holsboer F \& Rein T 2005 FK506-binding proteins 51 and 52 differentially regulate dynein interaction and nuclear translocation of the glucocorticoid receptor in mammalian cells. Journal of Biological Chemistry 280 4609-4616.

Zwain IH, Grima J \& Cheng CY 1992 Rat epididymal retinoic acidbinding protein: development of a radioimmunoassay, its tissue distribution, and its changes in selected androgen-dependent organs after orchiectomy. Endocrinology 131 1511-1526.

Received 29 August 2006

First decision 27 September 2006

Accepted 9 November 2006 